\title{
A Clustering Approach to Understanding Farmers' Success Strategies
}

\author{
Chinonso Etumnu* (D) and Allan W. Gray \\ Agricultural Economics, Purdue University, West Lafayette, IN, USA \\ ${ }^{*}$ Corresponding author. Email: cetumnu@purdue.edu
}

\begin{abstract}
This paper examines the prioritization of management factors by farmers that lead to the success of their farm business. The research also examines the heterogeneity of producer prioritization of different success strategies. Using a hierarchical clustering approach, we found that each farmer group prioritizes either managing costs, managing output prices, managing people, managing production, or managing assets. The results indicate that the farmer groups are heterogeneous in their prioritization of five strategic management factors. These results provide useful insights for farmers, farm input providers, and farm service providers.
\end{abstract}

Keywords: farm decision-making; farm management; farm strategy; managing assets; managing costs; managing output prices; managing people; managing production

JEL Classifications: Q13; Q16; Q19

\section{Introduction}

For commercial producers whose primary occupation is farming, maximizing profit for their farm business in a time of fierce competition is incredibly difficult (McBride and Johnson, 2006; Nivens, Kastens, and Dhuyvetter, 2002). Because of this, the relative importance of the farmer's decisions on the success of the business has increased dramatically. Farmers have to choose and prioritize management factors that directly affect their farm's performance (Kastens, Dhuyvetter, and Nivens, 2002). Which factors do farmers give priority to in order to increase the success of their farm business? Is it managing people, managing production, managing cost, managing output prices, or managing assets (land, equipment, and facilities)? Are farmers homogeneous in their business strategies, or are there heterogeneous patterns of producers pursuing different strategies for success? Are the management success strategies of livestock and crop producers similar or different? Understanding the heterogeneity of farmer priorities for management factors will allow those who serve farmers to consider tailoring offerings according to the farmer's preferred strategy.

The importance of key management factors in the success of farm businesses has previously received research attention (Holland et al., 2014; Lai et al., 2018), but these studies did not consider the similarities and differences between management strategies based on farmers' primary production activity. Holland et al. (2014) used choice-based data from the 2013 edition of the Large Commercial Producer Survey to identify the most important predetermined management factors as controlling costs and managing production. They also used a mixed logit model to identify that managing production, and controlling costs are strongly negatively correlated. However, they did not expound the potential differences and similarities between farmers in terms of their success

(C) The Author(s) 2020. This is an Open Access article, distributed under the terms of the Creative Commons Attribution licence (http:// creativecommons.org/licenses/by/4.0/), which permits unrestricted re-use, distribution, and reproduction in any medium, provided the original work is properly cited. 
strategies. Lai et al. (2018) used the same data as Holland et al. (2014) but employed a latent class model approach to find that farmers can be categorized based on their management strategies. They grouped farmers into production purists, cost control through people, production management through people, and commodity marketing-focused farmers. They noted that each of these groups perceive farm management priorities differently. Our analysis extends the work of Lai et al. (2018) in two important ways. First, our survey of producers asks them to rank the five basic management factors. The forced ranking provides a succinct way to gather producer opinions on the importance of these factors. However, it also makes it more difficult to find groups of producers with similar strategies. In this paper, we compute a weighted rank coefficient for each producer. This allows us to then use hierarchical clustering techniques to identify unique groups of farmer strategies that can be compared to the findings from the previous studies. Second, we explore the differences in management strategy clusters for crop farmers compared to livestock farmers to explore differences in the heterogeneity of management strategies across the two primary farm enterprise types.

This study uses data from the 2017 edition of the Purdue University Center for Food and Agricultural Business Large Commercial Producer Survey and a clustering analysis method. Our aim for conducting the cluster analysis is to understand the heterogeneity of managerial priorities of each farmer group based on their primary production activity. This is especially important because farm businesses differ in scale and type, and thus the managerial approaches of respective farmers might also differ. We found five groups of farmers: two farmer groups that consider managing cost as the most important activity, two groups that prioritize people management, and one group that prioritizes managing production. Furthermore, we found five clusters of farmers based on farm type-livestock or crop production. Each of these groups prioritizes either managing costs, managing output prices, managing people, managing production, or managing assets. However, the groups are heterogeneous regarding the relative importance of these management factors. Our findings provide evidence of the similarities and differences between farmers' management success strategies, which could be insightful for inputs and service providers, policy makers, and academics who provide managerial educational programs to farmers.

\section{Data}

The Center for Food and Agricultural Business at Purdue University conducts the Large Commercial Producers Survey every 5 years to elicit farmers' success strategies, buying behavior, risk perceptions, marketing segments, demographics, and other pertinent information. The data used in this study are from the 2017 edition of the survey. Numerous publications use data from previous editions of the survey (Gloy and Akridge, 1999, 2000; Gloy, Akridge, and Whipker, 2000; Ringelberg, Gunderson, and Widmar, 2016). For example, Hooper (1994) used data from the 1993 survey edition to segment the market for agricultural inputs using a nested approach. Gloy and Akridge (1999) used a similar approach with the 1998 version of the survey to find four distinct segments of commercial producers: convenience buyers, balance buyers, price buyers, and performance buyers. Using data from both the 1998 and 2003 versions of the survey, Alexander, Wilson, and Foley (2005) investigated if there are differences in producer market segments over time. This investigation was made possible because $76 \%$ of the questions in the 1998 survey were repeated in 2003. Alexander, Wilson, and Foley (2005) found an increase in the service, price, and performance market segments and a decrease in the convenience market segment. Borchers et al. (2012) used the 2008 version of the survey to explore how large commercial producers choose their input suppliers, segmenting the market in line with previous studies. The differences in market segments found by these studies over the years have important marketing implications for input suppliers and farmers. This study builds on this precedent, specifically on the works of 
Lai et al. (2018) and Holland et al. (2014), who used data from the 2013 version of the survey to examine farmers' success strategies.

In April 2017, the survey was mailed to farmers-15,300 were sent via U.S. mail. A marketing services provider, Infogroup, was recruited to contact farmers who did not complete the survey after multiple reminders. The response rate is as follows: 1,640 surveys were completed for a response rate of approximately $10.7 \%$ from the initial mailing. From the 1,640 surveys that were completed and returned, we used the listwise elimination method to exclude surveys that either did not complete the ranking or ranked the responses illogically. This reduced the final survey amount used in this study to 991, which comprises farmers who ranked their strategies and responded to several other questions, including their farm and demographic characteristics. The response rates in previous years of the survey were $7.5 \%$ in 2013 and $29 \%$ in 2008 (Alexander et al., 2009; Lai et al., 2018).

The main question of interest asks farmers to rank the most important management activity to the success of their farm business from one to five, one being the most important and five being the least important. Their options are managing people; managing production; managing/ controlling costs; managing output prices; and managing land, equipment, and facilities. Although these options are predetermined, they are a result of an extensive review of the literature and consultation with agribusiness leaders (Lai et al., 2018). For example, traditionally, the successful farmer is defined as someone who is hardworking, self-reliant, and religious, and someone who strives to preserve their farm for his family and community (Walter, 1995, 1996, 1997). However, with the rise in commercial agriculture and industrialization, the attributes of a successful farmer have been transformed into business-oriented, maximum production, technical efficiency, and innovation (Walter, 1996), but individual farmers may define success differently based on their on their personal goals for their farms, family, and community. Some farmers may define success based on how society perceives the ideal farmer-maybe through measures of wealth, profit, continuity of ownership, farm management, and farm living. Indeed, Walter (1996) suggested that farm magazines associate farm success stories with commercial values. However, because of the array of ways to define farm success, we did not specify any definition of success in the survey. Rather, we allowed the farmers to interpret success from their own perspective. Furthermore, we did not provide the farmers with any specific definitions of the five management factors that we asked them to consider. For example, we asked them to rank managing production as a factor in their success. There is no further definition of this factor, so respondents were left to interpret this on their own. Our interpretation of this factor is that it focuses on crop yields, milk production, and/or meat production.

The survey also asked farmers to identify their primary activity, either crop or livestock production. This question allows us to examine the management strategies of crop and livestock farmers separately. Other questions that are of interest elicit farm characteristics. We are able to determine farm size-midsize, commercial, or large - and the gross revenue of the farm based on these questions. We estimated the gross revenue based on the acres, crops, and number of livestock reported by farmers using the price of these products in 2016. We then categorized each farm business following Vilsack and Reilly (2012): US\$150,000-US\$999,000 (midsize), US $\$ 1,000,000$-US $\$ 4,999,999$ (commercial), and above US $\$ 5,000,000$ (large). Only farm businesses with estimated gross sales of at least US\$150,000 were included in this study to reduce the likelihood of contacting farmers whose primary source of livelihood is not farming. Other questions elicit the farmer's demographics such as age, educational level (from less than high school to doctorate), gender (male or female), and location. Figures 1 and 2 indicate the location of the primary state where each respondent's crop or livestock operation is located. The exact question prompts used in this study are provided in Appendix A. About $60 \%$ of the farmers who responded logically to all of the managerial strategy questions are crop producers, while $40 \%$ are livestock producers. Most (92\%) of them are male, have at least a 2-year college degree (68\%), and are above 40 years old (90\%). The size of their farm business varied: $48 \%$ recorded US $\$ 1$ million and above 


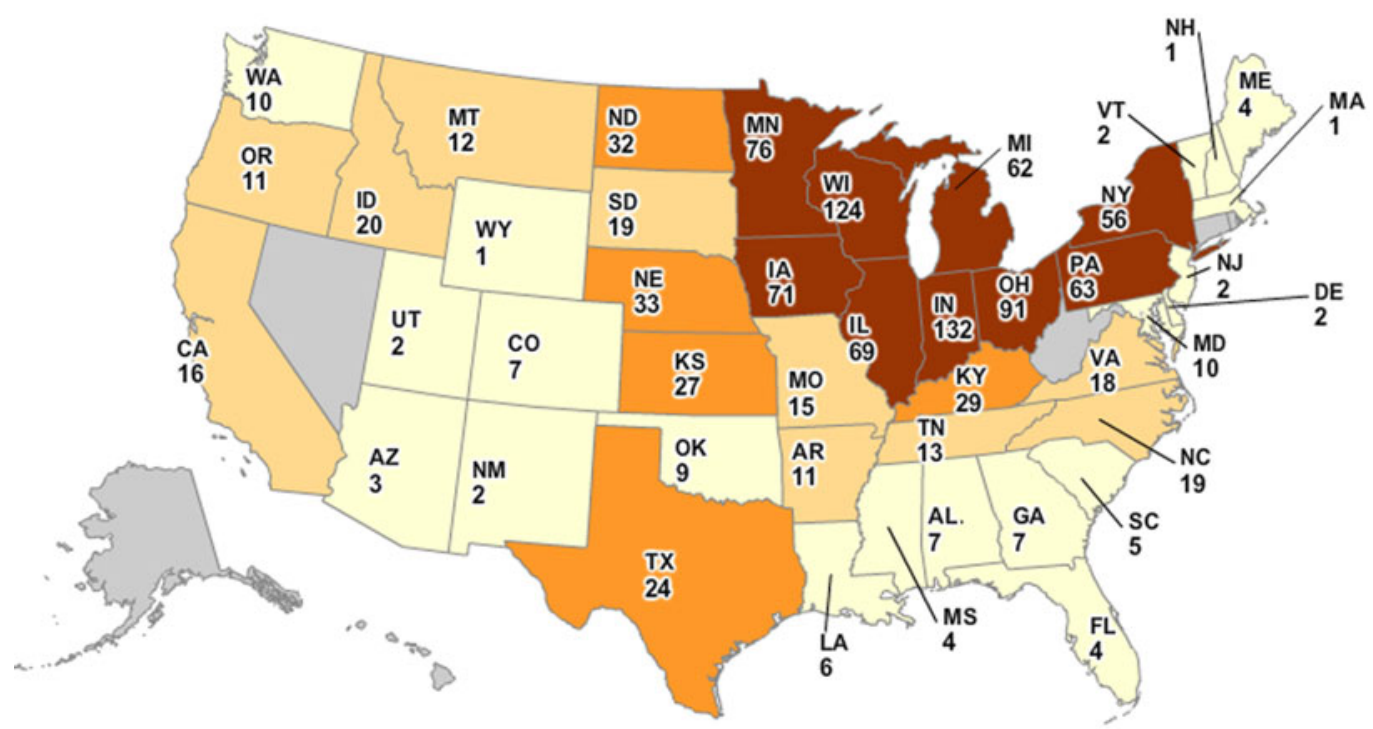

Figure 1. Geographic location of crop farmers in the survey.

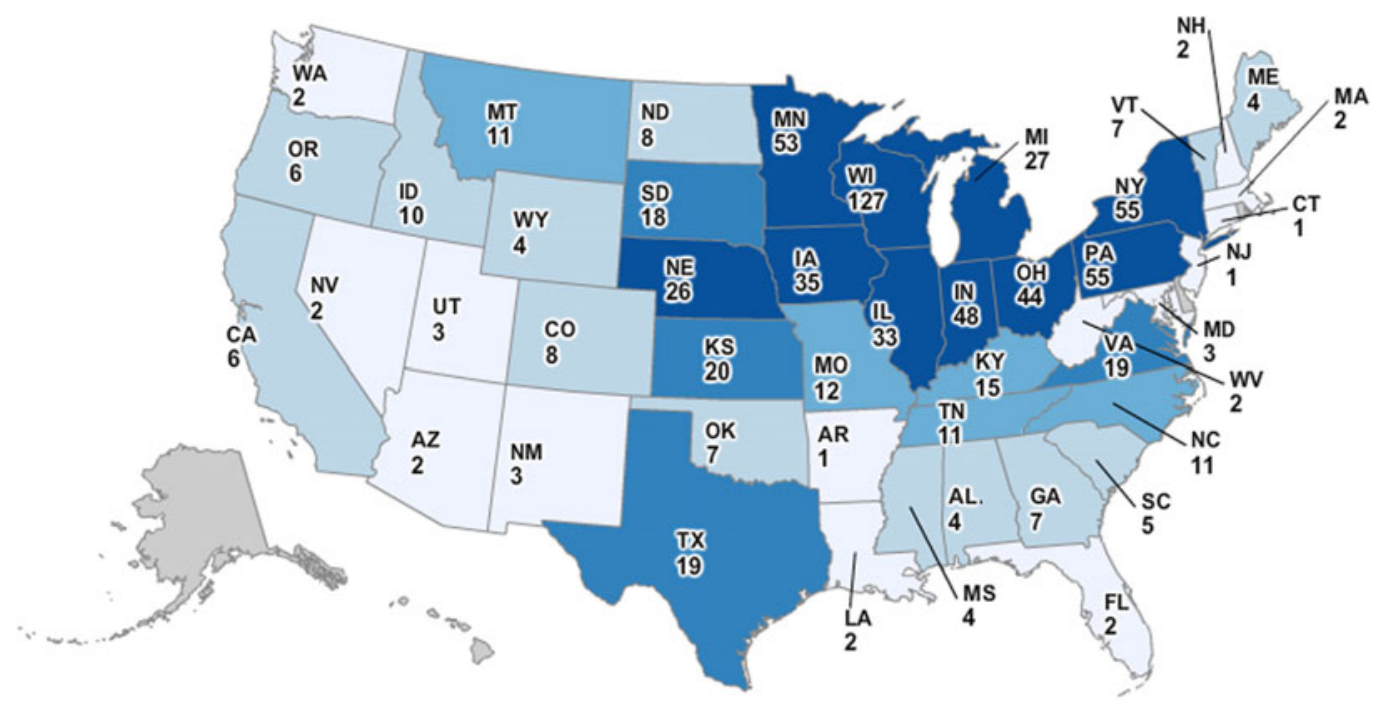

Figure 2. Geographic location of livestock farmers in the survey.

in sales in 2016, while 49\% recorded between US $\$ 100$ and US $\$ 500$ thousand in sales in the same year. These variables are consistent, but as expected, slightly different from the previous editions of the Large Commercial Producer Survey. We present a comprehensive summary of these variables in Table 1 for all farmers, crop producers, and livestock producers, respectively.

\section{Methods}

Our focus is on the types of strategies producers use to pursue success. That is, are there groups of producers who rank the success factors question in a similar manner? The ranking question makes 
Table 1. Summary of demographic and farm characteristics of the sample

\begin{tabular}{|c|c|c|c|}
\hline & All Farmers & Crop Farmers & Livestock Farmers \\
\hline \multicolumn{4}{|l|}{ Farm size } \\
\hline Mid-size & $486^{a}(49)^{b}$ & $275(46)$ & $211(53)$ \\
\hline Commercial & $352(36)$ & $236(10)$ & $116(29)$ \\
\hline Large & $153(15)$ & $81(14)$ & $72(18)$ \\
\hline \multicolumn{4}{|l|}{ Age (years) } \\
\hline $18-39$ & $89(10)$ & $62(11)$ & $27(7)$ \\
\hline $40-54$ & $166(18)$ & $86(16)$ & $80(22)$ \\
\hline $55-69$ & $473(52)$ & $280(50)$ & $193(52)$ \\
\hline $70+$ & $199(21)$ & $128(23)$ & 71 (19) \\
\hline \multicolumn{4}{|l|}{ Education } \\
\hline Less than high school & $25(3)$ & $6(1)$ & $19(5)$ \\
\hline High-school graduate & $276(30)$ & $161(29)$ & $115(31)$ \\
\hline 2-year degree & $200(21)$ & $115(20)$ & $85(22)$ \\
\hline 4-year degree & $351(38)$ & $232(41)$ & $119(32)$ \\
\hline Master's degree & $62(7)$ & $43(8)$ & $19(5)$ \\
\hline Doctorate & $20(2)$ & $6(1)$ & $14(4)$ \\
\hline \multicolumn{4}{|l|}{ Decision maker } \\
\hline Yes & $903(93)$ & $550(95)$ & $353(91)$ \\
\hline No & $64(7)$ & $31(5)$ & $33(9)$ \\
\hline Respondents & $991(100)$ & $592(100)$ & $399(100)$ \\
\hline
\end{tabular}

a Number of farmers in the category.

${ }^{b}$ Percentage of farmers.

it difficult to identify distinct groups of producers who answer similarly because of the correlation among the ranked factors. To overcome this difficulty, we use an agglomerative hierarchical clustering method, following the approach of Brentari, Dancelli, and Manisera (2016). An agglomerative hierarchical clustering method builds a hierarchy of clusters from bottom-up, grouping subjects, or elements that are most similar first, and then the nearest initial clusters until the hierarchy is completed (Kaufman and Rousseeuw, 2009). The ranked nature of our data suits this type of cluster analysis. We use a weighted rank correlation coefficient to emphasize the order of ranks in the clusters. Brentari, Dancelli, and Manisera (2016) suggest that using the weighted rank coefficient ensures that groups are based on the most important management strategies of farmers. Based on the consistency of the findings of previous studies, we use the following weighted rank coefficient developed by Salama and Quade (Tarsitano et al., 2009):

$$
\rho_{w}=1-2 \frac{\sum_{i=1}^{n}\left(r_{i}-q_{i}\right)^{2}\left(\left(\frac{1}{r_{i}}\right)+\left(\frac{1}{q_{i}}\right)\right)}{(n+1) \sum_{i=1}^{n} \frac{[2 i-(n+1)]^{2}}{i(n-i+1)}}
$$

where $i=1, \ldots, n$ is the number of success factors, and $R: r_{1}, r_{2}, \ldots, r_{i}, \ldots, r_{n}$ and $Q: q_{1}, q_{2}, \ldots, q_{i}, \ldots, q_{n}$ are the two rankings. Equation 1 only holds when there are no ties in the rankings. Recall that we removed responses whose rankings were either missing or illogical 
from the data for this analysis. The value of $\rho w$ varies from -1 to +1 because the denominator of equation 1 is the maximum of the numerator reached when there is zero correlation between the ranks (Brentari, Dancelli, and Manisera, 2016). Therefore, we transform the weighted rank correlation coefficient $\left(\rho_{w}\right)$ into a dissimilarity measure $(d)$, which ranges from 0 to 1 . There are several ways to do this transformation (Kaufman and Rousseeuw, 2009), but we follow the method used by Brentari, Dancelli, and Manisera (2016): $d=\left(1-\rho_{w}\right) / 2$. This produces an $m \times m$ dissimilarity matrix that is used in the agglomerative hierarchical clustering.

The choice of a clustering method depends on several factors. We chose the hierarchical method in this study because it appears to generate clusters that are useful and meaningful in the explanation of heterogeneity in farmers' success management strategies. It also has the advantage of being simple, requiring only the generation of the matrix described above to be implemented. Furthermore, there is no need to predetermine the number of clusters, which is required by other clustering techniques, although there may be a difficulty (which we did not have in this study) in deciding on the final clusters. There are two types of hierarchical clustering algorithms: agglomerative and divisive. We chose the agglomerative clustering (bottom-up), which starts with the individual cluster of objects and then merges the closest pair of clusters with the least inter-object dissimilarity until a single cluster is achieved. The definition of inter-cluster dissimilarity generates different methods of agglomerative hierarchical clustering such as single (nearest neighbor) linkage, average linkage, and complete (furthest neighbor) linked. As noted above, we use the complete linkage method in this study. The complete linkage method establishes groups based on the largest dissimilarity between the two individual objects to be clustered. Formally, we can represent the complete linkage function-the largest dissimilarity $(\mathrm{D}(\mathrm{A}, \mathrm{B}))$ between two management clusters A and B-as follows (Kaufman and Rousseeuw, 2009):

$$
D(A, B)=\max _{a \in A, b \in B} d(a, b)
$$

where $d(a, b)$ is the distance between elements $\mathrm{a} \in \mathrm{A}$ and $\mathrm{b} \in \mathrm{B}$, and $\mathrm{A}$ and $\mathrm{B}$ are two sets of clusters. We used the R package to perform the complete linkage cluster analysis. However, deciding on the resulting number of clusters raises questions because there is not a systematically agreed way to make the decision (Brentari, Dancelli, and Manisera, 2016).

\section{Results and discussion}

Figure 3 shows that $36 \%$ of the farmers ranked managing costs as the most important management factor, closely followed by managing production (34\%), then managing people (19\%), managing assets (19\%), and managing output prices (9\%). Conversely, the farmers consider managing people (39\%) and managing output prices (29\%) as the least important management factors to the success of a farm business. These results seem intuitive. For instance, given that there are many factors that influence output prices other than the farmers' decisions such as global demand and supply of agricultural produce, international trade, weather conditions, and events in other sectors of the economy that directly affect agricultural prices, most farmers consciously considered managing output prices as the least important strategic management factor. Equally, as expected, it appears that the farmers focus on managing their costs and production to boost their profits.

We disaggregate the sample into livestock and crop producers in line with our objective of understanding the differences and similarities between the groups when compared to the entire sample. On one hand, there are 592 crop farmers in the sample. To these farmers, managing costs $(37 \%)$, closely followed by managing production $(32 \%)$, and then managing people $(16 \%)$ are the principal management factors to their success, while managing people (45\%) and managing output prices (22\%) appear to be the least important management factors to them (Figure 4). On the other hand, 399 farmers in the sample primarily raise livestock. Among these farmers, $38 \%, 36 \%$, and $24 \%$ rank managing production, managing costs, and managing people as 


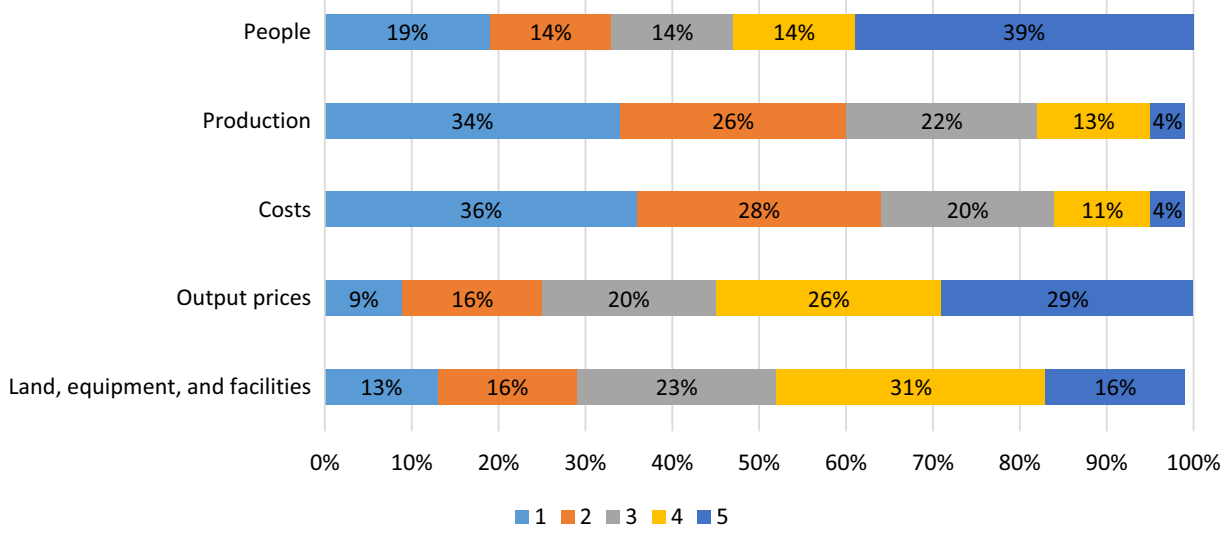

Figure 3. Importance of management factors to farmers' success for all farmers.



Figure 4. Importance of management factors to farmers' success for crop armers.

the most important management factors, respectively (Figure 5). Among the same group of farmers, $40 \%$ and $32 \%$ consider managing output prices and managing people the least important management factors. However, the results of the clustering analysis presented below highlight heterogeneity among the farmers.

Table 2 examines the question of which management factors farmers prioritize by presenting a relative ranking of the management factors based on their means. The results indicate that, from most to least important, the management factors important for farmers' success are managing costs, managing production, and managing assets, whereas managing output prices and managing people interchange positions. In addition, Table 2 compares the relative rankings of the management factors for farmers' success based on farmers' primary activity. Among the management factors, only managing people and managing output prices have statistically different means of relative ranking for the comparisons between the entire sample and crop/livestock farmers, and between crop and livestock farmers. However, the mean relative ranking of managing people for crop farmers (3.78) is higher (meaning less important) than the mean of managing people for livestock farmers (3.31). Conversely, the mean relative ranking of managing output prices for crop farmers (3.55) is lower than the mean relative ranking of managing output prices for livestock 
Table 2. Comparison of management factors by farmer demographics

\begin{tabular}{|c|c|c|c|c|c|c|}
\hline & $\begin{array}{l}\text { Managing } \\
\text { People }\end{array}$ & $\begin{array}{l}\text { Managing } \\
\text { Production }\end{array}$ & $\begin{array}{l}\text { Managing } \\
\text { Costs }\end{array}$ & $\begin{array}{c}\text { Managing } \\
\text { Output Prices }\end{array}$ & $\begin{array}{c}\text { Managing } \\
\text { Land, Equipment, } \\
\text { and Facilities }\end{array}$ & $\begin{array}{c}\text { Number of } \\
\text { Farmers }\end{array}$ \\
\hline All farmers & $3.59(1.52)^{a}$ & $2.37(1.16)$ & $2.20(1.16)$ & $3.55(1.30)$ & $3.29(1.24)$ & 991 \\
\hline \multicolumn{7}{|l|}{ Primary activity } \\
\hline Crop farmers & $3.78(1.46)$ & $2.41(1.17)$ & $2.21(1.19)$ & $3.26(1.31)$ & $3.34(1.28)$ & 592 \\
\hline Livestock farmers & $3.31(1.57)$ & $2.30(1.15)$ & $2.20(1.13)$ & $3.97(1.16)$ & $3.22(1.18)$ & 399 \\
\hline \multicolumn{7}{|l|}{ Farm size } \\
\hline Midsize & $4.13(1.35)$ & $2.28(1.13)$ & $2.11(1.10)$ & $3.45(1.20)$ & $3.03(1.21)$ & 486 \\
\hline Commercial & $3.28(1.51)$ & $2.40(1.18)$ & $2.27(1.21)$ & $3.59(1.36)$ & $3.46(1.22)$ & 352 \\
\hline Large & $2.59(1.32)$ & $2.56(1.22)$ & $2.35(1.24)$ & $3.77(1.43)$ & $3.73(1.15)$ & 153 \\
\hline \multicolumn{7}{|l|}{ Age (years) } \\
\hline $18-39$ & $2.72(1.51)$ & $2.52(1.16)$ & $2.35(1.21)$ & $3.82(1.32)$ & $3.60(1.23)$ & 89 \\
\hline $40-54$ & $3.30(1.50)$ & $2.25(1.16)$ & $2.28(1.14)$ & $3.78(1.14)$ & $3.40(1.27)$ & 166 \\
\hline $55-69$ & $3.72(1.49)$ & $2.29(1.15)$ & $2.20(1.18)$ & $3.53(1.28)$ & $3.27(1.20)$ & 473 \\
\hline $70+$ & $3.86(1.46)$ & $2.53(1.17)$ & $2.11(1.12)$ & $3.41(1.30)$ & $3.09(1.29)$ & 199 \\
\hline \multicolumn{7}{|l|}{ Education } \\
\hline $\begin{array}{l}\text { Less than high } \\
\text { school }\end{array}$ & $4.12(1.39)$ & $2.40(1.12)$ & $1.80(0.96)$ & $3.92(1.04)$ & $2.76(1.05)$ & 25 \\
\hline $\begin{array}{l}\text { High-school } \\
\text { graduate }\end{array}$ & $4.09(1.37)$ & $2.24(1.12)$ & $2.17(1.10)$ & $3.43(1.20)$ & $3.07(1.26)$ & 276 \\
\hline 2-year degree & $3.68(1.46)$ & $2.27(1.13)$ & $2.14(1.17)$ & $3.60(1.27)$ & $3.32(1.20)$ & 200 \\
\hline 4-year degree & $3.13(1.54)$ & $2.45(1.21)$ & $2.28(1.21)$ & $3.61(1.36)$ & $3.53(1.18)$ & 351 \\
\hline Master's degree & $3.45(1.49)$ & $2.63(1.20)$ & $2.32(1.26)$ & $3.42(1.49)$ & $3.12(1.29)$ & 62 \\
\hline Doctorate & $3.05(1.57)$ & $2.45(1.05)$ & $2.45(1.05)$ & $4.40(0.99)$ & $2.65(1.42)$ & 20 \\
\hline
\end{tabular}

aNote that 1 represents "most important" and 5 represents "least important." Standard deviation is in bracket.

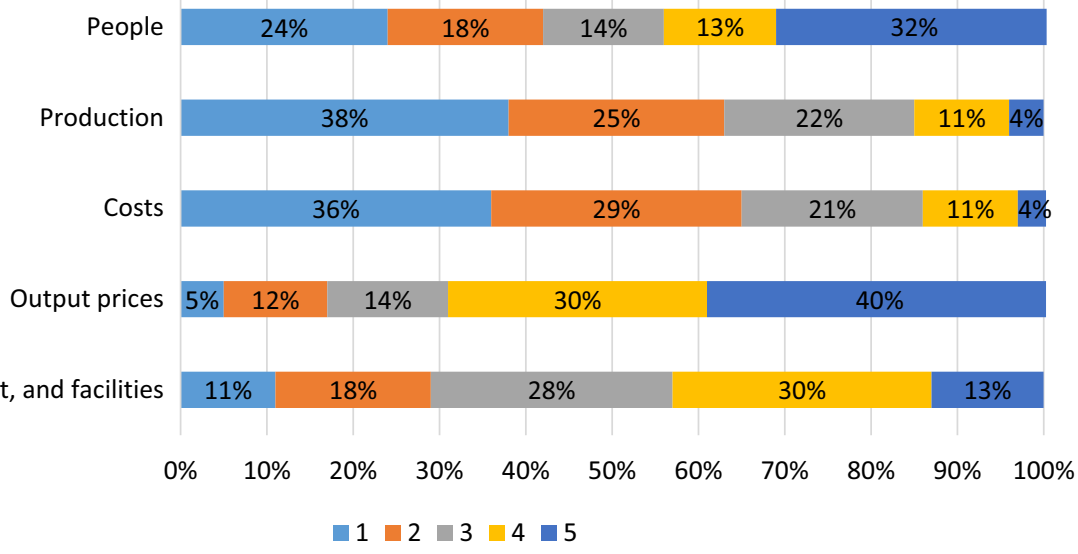

Figure 5. Importance of management factors to farmers' success for livestock farmers. 
farmers (3.97). One possible explanation for the results on managing people might be the differences in labor requirement for livestock and crop farms. Moreover, as farms become more mechanized, the size and composition of farm labor continue to change, and there appears to be marked differences in these changes across farm types. Likewise, the differences in the relative ranking of managing output prices can be attributed to how crops and livestock are marketed and sold. Although there are diverse agricultural marketing strategies, commodity crops such as wheat, corn, and soybeans and livestock such as hogs and cattle are often marketed through commodity markets. Direct marketing contracts between grocery retailers and farmers of fresh fruits and vegetable do exist, as well as local farmers markets and auction sales. Therefore, the level of control farmers have regarding output prices varies according to the product type, as well as their marketing strategies.

Table 2 also reports the results of the relative ranking of management factors based on the size of their farm operation. The key question addressed is whether the management factors prioritized by midsize, commercial, and large farmers are the same or different for each of these groups. We find that midsize, commercial, and large farmers all prioritize managing costs and managing production, while large farmers also emphasize people management. However, based on an analysis of variance test, we find that there is a significant difference across the three farm size groups. Midsize farmers prioritize managing costs and managing production more than commercial farmers and then large farmers. Other management factors are also statistically different across the three farm size groups. We obtained similar results in terms of the age of the farmers and their education. All the results presented in Table 2 indicate heterogeneity in how farmers prioritize management factors based on their specific demographics.

We also examine the heterogeneity of farmer priorities of the management factors using cluster analysis. Table 3 summarizes the results. Recall that the clustering strategy adopted in this study draws from how the producers ranked the five factors. Thus, when a producer ranks a particular factor higher, another factor must rank lower. Our clustering methodology recognizes this correlation. In addition, although there are 120 possible ways to rank the five management factors, the clustering methodology allows us to identify five distinct groups of farmers who prioritize the five management strategies similarly. Therefore, the clusters presented below represent particular orderings of the five factors. That is, the rank of each factor in the cluster matters relative to the rank in the other clusters.

For example, in the "all farmers" segment (crop and livestock producers combined) in Table 3, Cluster 1 has 228 farmers who are predicted to identify managing costs and managing land and buildings as the top two management factors. Cluster 2 farmers, in contrast, are predicted to prioritize managing costs and managing output prices as the top two factors. Clusters 3 and 4 are similar in ranking people management as the top management factor, but Cluster 3 identifies cost management as the second most important factor while Cluster 4 identifies production management as the second most important factor. Cluster 5 , meanwhile, prioritizes managing production and managing costs as the top two management success factors.

When disaggregating crop and livestock farmer data sets before conducting the clustering algorithm, we see a different pattern of prioritization (see Table 3). For crop farmers, Cluster 1 farmers prioritize managing costs; Cluster 2 farmers prioritize managing output prices; Cluster 3 farmers prioritize managing people; Cluster 4 farmers prioritize managing production; and Cluster 5 farmers prioritize managing assets. Similarly, for the livestock farmers, each cluster of farmers prioritizes a particular management factor. Even though prioritizing managing costs suggests that yields are being sacrificed, the results of the cluster analysis for all farmers based on their farm type demonstrate considerable heterogeneity among farmers with regard to their prioritized management factors.

Overall, we found that the farmers ranked cost management and production management as the most important success factors. We believe that the key message is the combination of 
Table 3. Prioritization of management factors by identified clusters of farmer rankings

\begin{tabular}{|c|c|c|c|c|c|c|}
\hline & $\begin{array}{l}\text { Managing } \\
\text { People }\end{array}$ & $\begin{array}{l}\text { Managing } \\
\text { Production }\end{array}$ & $\begin{array}{l}\text { Managing } \\
\text { Costs }\end{array}$ & $\begin{array}{c}\text { Managing } \\
\text { Output Prices }\end{array}$ & $\begin{array}{c}\text { Managing Land, } \\
\text { Equipment, and } \\
\text { Facilities }\end{array}$ & $\begin{array}{c}\text { Number of } \\
\text { Farmers }\end{array}$ \\
\hline \multicolumn{7}{|l|}{ All farmers } \\
\hline Cluster 1 & $4.35^{\mathrm{a}}(5)$ & $2.88(3)$ & $1.64(1)$ & $4.16(4)$ & $1.95(2)$ & 228 \\
\hline Cluster 2 & $4.34(5)$ & $3.07(3)$ & $1.71(1)$ & $1.98(2)$ & $3.88(4)$ & 251 \\
\hline Cluster 3 & $1.75(1)$ & $2.29(3)$ & $2.33(2)$ & $4.41(5)$ & $4.22(4)$ & 242 \\
\hline Cluster 4 & $1.81(1)$ & $2.21(2)$ & $4.29(4)$ & $4.47(5)$ & $2.21(2)$ & 75 \\
\hline Cluster 5 & $4.70(5)$ & $1.00(1)$ & $2.53(2)$ & $3.42(4)$ & $3.35(3)$ & 195 \\
\hline \multicolumn{7}{|l|}{ Crop farmers } \\
\hline Cluster 1 & $3.78(5)$ & $2.40(2)$ & $1.41(1)$ & $3.69(3)$ & $3.72(4)$ & 248 \\
\hline Cluster 2 & $3.55(4)$ & $3.42(3)$ & $2.65(2)$ & $1.36(1)$ & $4.02(5)$ & 95 \\
\hline Cluster 3 & $1.00(1)$ & $2.91(2)$ & $4.06(5)$ & $3.74(4)$ & $3.29(3)$ & 35 \\
\hline Cluster 4 & $4.59(5)$ & $1.00(1)$ & $2.69(2)$ & $3.25(3)$ & 3.47 (4) & 130 \\
\hline Cluster 5 & $3.94(4)$ & $3.29(3)$ & $2.54(2)$ & $3.96(5)$ & $1.00(1)$ & 84 \\
\hline \multicolumn{7}{|c|}{ Livestock farmers } \\
\hline Cluster 1 & $4.08(4)$ & $1.53(1)$ & $2.21(2)$ & $4.28(5)$ & $2.90(3)$ & 197 \\
\hline Cluster 2 & $1.44(1)$ & $2.86(3)$ & $2.28(2)$ & $4.63(5)$ & $3.80(4)$ & 104 \\
\hline Cluster 3 & $4.15(5)$ & $3.35(3)$ & $1.00(1)$ & $2.96(2)$ & $3.54(4)$ & 54 \\
\hline Cluster 4 & $3.28(2)$ & 3.44 (3) & $3.72(5)$ & $3.56(4)$ & $1.00(1)$ & 18 \\
\hline Cluster 5 & 3.23 (3) & $2.96(2)$ & $3.23(3)$ & $1.46(1)$ & $4.12(5)$ & 26 \\
\hline
\end{tabular}

aNote that 1 represents "most important" and 5 represents "least important"; the predicted rank for each cluster is in parentheses.

managing output and costs such that the cost per unit produced is minimized. This addresses the issue of cutting costs in ways that are detrimental to productivity. In fact, the majority of farmers in both the crop and livestock segments (64\% and 49\%, respectively) rank managing production and managing costs as the first and second most important strategies. We believe this to mean that the majority of farmers believe that their core strategic discipline is operational excellence in the vernacular of Treacy and Wiersma (1993). Even in the livestock group, the second largest cluster of producers (24\%) still focused on managing factors of production as the top three strategies where people management was first, followed by costs, and then production. Again, this would seem to be in line with the concept of operational excellence as the key success strategy of most farms.

Another key finding in our study is that most of the farmers did not rank managing output prices as important as managing costs or managing production. This raises a question of whether the farmers use consultants to manage their marketing. We address this question in Table 4. Table 4 presents the results of a survey question that elicits how the farmers carry out their marketing. Table 4 also disaggregates the findings by farm types and farm clusters. For the all farmers category, we found that $81 \%$ of the farmers said that they do marketing themselves, while $5 \%, 8 \%$, and $6 \%$ said that it is done by a farm employee, they do not do marketing, or it is done by a contractor, respectively. This result persists even when the sample is disaggregated into livestock farmers and crop farmers; $86 \%$ of crop farmers and $74 \%$ of livestock farmers said that they do 
Table 4. Primary marketing responsibilities segmented by farmer clusters

\begin{tabular}{|c|c|c|c|c|c|}
\hline & Myself & Farm Employee & Don't Do It & Contractor & Number of Farmers \\
\hline \multicolumn{6}{|l|}{ All farmers } \\
\hline Cluster 1 & $182^{\mathrm{a}}(81)^{\mathrm{b}}$ & $6(3)$ & $23(10)$ & $13(6)$ & 224 \\
\hline Cluster 2 & $213(89)$ & $10(4)$ & $6(3)$ & $11(5)$ & 240 \\
\hline Cluster 3 & $163(70)$ & $18(8)$ & $29(13)$ & $22(9)$ & 232 \\
\hline Cluster 4 & $54(73)$ & $8(11)$ & $8(11)$ & $4(5)$ & 74 \\
\hline Cluster 5 & $165(88)$ & $4(2)$ & $13(7)$ & $6(3)$ & 188 \\
\hline Number of farmers & $777(81)$ & $46(5)$ & $79(8)$ & $56(6)$ & 958 \\
\hline \multicolumn{6}{|l|}{ Crop farmers } \\
\hline Cluster 1 & $269(88)$ & $15(5)$ & $6(2)$ & $16(5)$ & 306 \\
\hline Cluster 2 & $40(89)$ & $0(0)$ & $2(4)$ & $3(7)$ & 45 \\
\hline Cluster 3 & $41(72)$ & $9(16)$ & $4(7)$ & $3(5)$ & 57 \\
\hline Cluster 4 & $73(85)$ & $4(5)$ & $3(3)$ & $6(7)$ & 86 \\
\hline Cluster 5 & $69(90)$ & $2(3)$ & $2(3)$ & $4(5)$ & 77 \\
\hline Number of farmers & $492(86)$ & $30(5)$ & $17(3)$ & $32(6)$ & 571 \\
\hline \multicolumn{6}{|l|}{ Livestock farmers } \\
\hline Cluster 1 & $140(73)$ & $5(3)$ & $33(17)$ & $13(7)$ & 191 \\
\hline Cluster 2 & $70(70)$ & $4(4)$ & $21(21)$ & $5(5)$ & 100 \\
\hline Cluster 3 & $45(85)$ & $3(6)$ & $4(8)$ & $1(2)$ & 53 \\
\hline Cluster 4 & $11(61)$ & $2(11)$ & $2(11)$ & $3(17)$ & 18 \\
\hline Cluster 5 & $19(76)$ & $2(8)$ & $2(8)$ & $2(8)$ & 25 \\
\hline Number of farmers & $285(74)$ & $16(4)$ & $62(16)$ & $24(6)$ & 387 \\
\hline
\end{tabular}

${ }^{a}$ Number of farmers in the category.

bercentage of farmers.

Note: Note that the sample size of the clusters here is a bit different due to missing responses to the marketing questions.

marketing themselves. We believe that the success strategies ranking is a recognition amongst most producers that they have very little control over long-term prices, and while managing short-run volatility of prices is important, it would be difficult to strategically position the farm for success based on a strategy of achieving premium prices. As such, their strategies are focused on things they can control (productivity and costs) that allow them to survive whatever long-term price impacts they may face. Furthermore, although the 2013 survey was conducted during a period of record high prices and near-record U.S. net farm income while the 2017 survey captures the adjustment from record profit to a more normal level of profitability, Lai et al. (2018) and Holland et al. (2014) found essentially the same groupings that we found when they used the 2013 data. This supports our notion that price management is not the long-term success strategy used by most producers since the same success strategies were pursued in both 2013 and 2017.

Table 5 presents the demographics of each of the clusters for all farmers. For the five clusters in this group, $58 \%$ of farmers in Cluster 1 are crop farmers, $76 \%$ of farmers in Cluster 2 are crop farmers, $46 \%$ in Cluster 3, 44\% in Cluster 4, and 63\% in Cluster 5. In terms of farm size, a majority of farmers in Cluster 1 (64\%), Cluster 2 (51\%), and Cluster 5 (63\%) are midsize, while a majority of 
Table 5. Demographic and farm characteristics for all farmers by clusters

\begin{tabular}{|c|c|c|c|c|c|}
\hline & Cluster 1 & Cluster 2 & Cluster 3 & Cluster 4 & Cluster 5 \\
\hline \multicolumn{6}{|l|}{ Primary activity } \\
\hline Crop producers & $133^{\mathrm{a}}(58)^{\mathrm{b}}$ & $191(76)$ & $112(46)$ & $33(44)$ & $123(63)$ \\
\hline Livestock producers & $95(42)$ & $60(24)$ & $130(54)$ & $42(56)$ & $72(37)$ \\
\hline \multicolumn{6}{|l|}{ Farm size category } \\
\hline Mid-size & $145(64)$ & $127(51)$ & $64(26)$ & $27(36)$ & $123(63)$ \\
\hline Commercial & $61(27)$ & $89(35)$ & $111(46)$ & $30(40)$ & $61(31)$ \\
\hline Large & $22(10)$ & $35(14)$ & $67(28)$ & $18(24)$ & $11(6)$ \\
\hline \multicolumn{6}{|l|}{ Age } \\
\hline $18-39$ & $18(8)$ & $18(8)$ & $35(16)$ & $9(13)$ & $9(5)$ \\
\hline $40-54$ & $33(15)$ & $32(14)$ & $53(24)$ & $15(21)$ & $33(18)$ \\
\hline $55-69$ & $110(50)$ & $118(53)$ & $104(46)$ & $36(51)$ & $105(57)$ \\
\hline $70+$ & $61(27)$ & $56(25)$ & $33(15)$ & $11(15)$ & $38(21)$ \\
\hline \multicolumn{6}{|l|}{ Education } \\
\hline Less than high school & $11(5)$ & $5(2)$ & $2(1)$ & $2(3)$ & $5(3)$ \\
\hline High-school graduate & $73(33)$ & $73(32)$ & $43(19)$ & $17(24)$ & $70(38)$ \\
\hline 2-year degree & $48(22)$ & $45(20)$ & $50(22)$ & $16(22)$ & $41(22)$ \\
\hline 4-year degree or higher & $90(40)$ & $105(46)$ & $132(58)$ & $37(51)$ & $69(38)$ \\
\hline Respondents $^{c}$ & $228(23)$ & $251(25)$ & $242(24)$ & $75(8)$ & $195(20)$ \\
\hline
\end{tabular}

a Number of farmers.

bercentage of farmers within the cluster.

"Respondents" only. The number in parentheses is the percentage of the total sample.

farmers in Cluster $3(74 \%)$ and Cluster 4 (64\%) are categorized as commercial or large. Cluster 5 has the highest percentage of farmers above 55 years of age (78\%) within the cluster, while Clusters 3 and 4 show the highest percentage of producers less than 55 years of age with $40 \%$ and $34 \%$, respectively. Clusters 3 and 4 have the highest percentage of college-educated producers at $58 \%$ and $51 \%$, respectively.

Table 6 highlights the demographics of the crop farm clusters. A majority of farmers in Cluster $1(45 \%)$, Cluster $4(55 \%)$, and Cluster $5(56 \%)$ are categorized as midsize, while a majority of crop farmers in Cluster $2(66 \%)$ and Cluster $3(63 \%)$ are categorized as commercial or large. Crop farm Cluster 4 has the highest percentage of crop farmers greater than 55 years old $(79 \%)$, while crop farm Cluster 2 is the youngest with $31 \%$ below age 55 . Crop farm Clusters 2 and 3 have the highest percentage of college-educated producers at $62 \%$ and $66 \%$, respectively.

Table 7 highlights the demographics of the livestock farm clusters. For the five clusters of livestock farmers, a majority of farmers in Cluster 2 (78\%) and Cluster 5 (58\%) are categorized as commercial or large, while the other three clusters have the majority of farmers categorized as midsize. Livestock farm Cluster $3(80 \%)$ has the highest percentage of livestock farmers greater than 55 years old. Cluster 2 has the highest percentage below 55 years old at 33\%. Finally, livestock farm Clusters 2 and 5 have the highest percentage of college-educated producers at $51 \%$ and $54 \%$, respectively. 
Table 6. Demographic and farm characteristics for crop farmers by clusters

\begin{tabular}{|c|c|c|c|c|c|}
\hline Variables & Cluster 1 & Cluster 2 & Cluster 3 & Cluster 4 & Cluster 5 \\
\hline \multicolumn{6}{|l|}{ Farm size category } \\
\hline Mid-size & $112^{a}(45)^{b}$ & $32(34)$ & $13(37)$ & $71(55)$ & $47(56)$ \\
\hline Commercial & $101(41)$ & $46(48)$ & $15(43)$ & $46(35)$ & $28(33)$ \\
\hline Large & $35(14)$ & $17(18)$ & $7(20)$ & $13(10)$ & $9(11)$ \\
\hline \multicolumn{6}{|l|}{ Age } \\
\hline $18-39$ & $25(11)$ & $16(18)$ & $7(22)$ & $5(4)$ & $9(11)$ \\
\hline $40-54$ & $37(16)$ & $11(13)$ & $2(6)$ & $22(18)$ & $14(18)$ \\
\hline $55-69$ & $122(53)$ & $40(46)$ & $14(44)$ & $71(57)$ & $33(41)$ \\
\hline $70+$ & $48(21)$ & $20(23)$ & $9(28)$ & $27(22)$ & $24(30)$ \\
\hline \multicolumn{6}{|l|}{ Education } \\
\hline Less than high school & $4(2)$ & $1(1)$ & $1(3)$ & $0(0)$ & $0(0)$ \\
\hline High-school graduate & $67(29)$ & $14(16)$ & $6(18)$ & $43(34)$ & $31(39)$ \\
\hline 2-year degree & $46(20)$ & $19(21)$ & $4(12)$ & $30(24)$ & $16(20)$ \\
\hline 4-year degree & $128(50)$ & $56(62)$ & $22(66)$ & $52(41)$ & $33(41)$ \\
\hline Respondents ${ }^{c}$ & $248(42)$ & $95(16)$ & $35(6)$ & $130(22)$ & $84(14)$ \\
\hline
\end{tabular}

a Number of farmers.

bercentage of farmers within the cluster.

"Respondents" only. The number in parentheses is the percentage of the total sample.

Table 7. Demographic and farm characteristics for livestock farm clusters

\begin{tabular}{|c|c|c|c|c|c|}
\hline Variables & Cluster 1 & Cluster 2 & Cluster 3 & Cluster 4 & Cluster 5 \\
\hline \multicolumn{6}{|l|}{ Farm size category } \\
\hline Mid-size & $135^{a}(69)^{b}$ & $26(25)$ & $27(50)$ & $12(67)$ & $11(42)$ \\
\hline Commercial & $44(22)$ & $47(45)$ & $16(30)$ & $5(28)$ & $4(16)$ \\
\hline Large & $18(9)$ & $31(30)$ & $11(20)$ & $1(5)$ & $11(42)$ \\
\hline \multicolumn{6}{|l|}{ Age } \\
\hline $18-39$ & $16(9)$ & $8(8)$ & $1(2)$ & $1(6)$ & $1(4)$ \\
\hline $40-54$ & $40(22)$ & $24(24)$ & $8(17)$ & $3(18)$ & $5(21)$ \\
\hline $55-69$ & $96(52)$ & $51(52)$ & $25(54)$ & $9(53)$ & $12(50)$ \\
\hline $70+$ & $34(18)$ & $15(15)$ & $12(26)$ & $4(24)$ & $6(25)$ \\
\hline \multicolumn{6}{|l|}{ Education } \\
\hline Less than high school & $14(8)$ & $2(2)$ & $3(7)$ & $0(0)$ & $0(0)$ \\
\hline High-school graduate & $68(37)$ & $19(20)$ & $14(30)$ & $5(28)$ & $9(38)$ \\
\hline 2-year degree & $43(23)$ & $26(27)$ & $9(20)$ & $5(28)$ & $2(8)$ \\
\hline 4-year degree & $61(33)$ & $50(51)$ & $20(43)$ & $8(44)$ & $13(54)$ \\
\hline Respondents $^{c}$ & $197(49)$ & $104(26)$ & $54(14)$ & $18(5)$ & $26(7)$ \\
\hline
\end{tabular}

${ }^{\mathrm{b}}$ Percentage of farmers within the cluster.

"Respondents" only. The number in parentheses is the percentage of the total sample. 


\section{Conclusion}

Our goal in this paper is to better understand farmer priorities for management factors that they believe influence the success of their farm business. To achieve this goal, we examined farmers' management priorities using a hierarchical clustering technique that allows emphasis to be placed on the highest-ranked management factors. The management factors were ranked from the most (1) to the least (5) important by the farmers. We obtained a dissimilarity matrix through a weighted rank coefficient and used it to cluster the sample of farmers. We then compared the groups resulting from the clustering to the entire sample and to the disaggregated samples of crop and livestock producers.

Our analysis of the resulting clusters is primarily based on a comparison of the ranked management factors, as well as the demographic characteristics of the farmers. The general result of the ranking of management factors indicates that farmers prioritized managing costs and production, which holds up even in the disaggregated samples of crop and livestock producers. However, the results of the cluster analysis revealed significant heterogeneity among the prioritized management strategies and the combined sample and disaggregated sample of crop and livestock farmers. The results of the clustering indicate that there are distinct groups of farmers who put more emphasis on different management factors. Although managing costs and production still represent a large proportion of farmers, managing people, managing assets, and managing output prices were selected by unique groups of farmers as the topmost management factors for the success of their farm business. Overall, it appears that the farmers generally considered managing output prices as the least important management factor for success. This result is perhaps intuitive since output prices appear to be the factor that is least under the control of the farmers. This interpretation is corroborated by the survey question that focuses on how the farmers carry out marketing, which shows that more than three quarters of the farmers said that they do not do marketing.

The demographic characteristics of each cluster reveal some interesting features for the groups. For the overall sample, farmers in Clusters 3 and 4 are generally larger, younger, and more educated. These two clusters combined represent $32 \%$ of all farmers (24\% for Cluster 3 and $8 \%$ for Cluster 4 ). These two clusters prioritize people management as the most important management factor with Cluster 3 prioritizing cost and production as second and third most important, while Cluster 4 prioritizes production and asset management as the next most important factors. From the perspective of agribusinesses serving these segments, recognition of the importance of people management to the business and the role of productivity will be important in the value proposition.

For the crop farm sample, Cluster 2 is generally larger, younger, and more educated than the other clusters. This cluster prioritizes product prices and costs as the top two management factors, suggesting margin management as a key success factor. This group represents $16 \%$ of crop farmers. However, the largest cluster, Cluster 1, represents $42 \%$ of all crop producers. This cluster of crop farmers prioritizes cost and production as the top two factors. The demographics suggest that this group is somewhat larger than most of the other clusters (excluding Cluster 2), but with respect to age and education, the cluster does not appear to stand out from the other clusters. This suggests that crop farmers, relative to the combined sample, are a more homogeneous group in general. Input and service providers should recognize that cost and production management are the critical factors for crop farmers, suggesting cost per unit of output or productivity is the driving decision factor for a large proportion of crop farms.

For the livestock farm sample, Clusters 2 and 5 are generally larger, younger, and more educated. These two clusters represent $33 \%$ of all livestock producers in the sample. Cluster 2 is the more important group from the standpoint of cluster size with $26 \%$ of the sample in this cluster. Cluster 2 prioritizes people management, cost management, and production management, respectively. Cluster 1 is the largest livestock cluster with $49 \%$ of the sample. Compared to Cluster 2, Cluster 1 consists of farms that are smaller, older, and less educated. Cluster 1 prioritizes 
production management, cost management, and asset management, respectively. But the key differentiator between Cluster 2 and Cluster 1's success strategies is the role of people management, likely reflective of their size differences. For Cluster 2, it seems clear that while cost and production management are decision priorities similar to Cluster 1, input and service providers would do well to understand the organizational and decision structure of the farms in this group because they are likely to be more complicated and sophisticated in their decision structure.

Overall, the results of this study are consistent with other research that has examined farmer business strategies. However, our results have illustrated the heterogeneity that exists in farmer priorities of the various management strategies. The results indicate that crop and livestock farmers differ in important ways in management priorities. In each sector, there are distinct clusters of farmers who prioritize different management factors, and in some cases, these distinct clusters have demographic features that stand out from the larger groups. Nonetheless, in both crop and livestock sectors, there is a large cluster of producers that remain relatively homogenous. Further research could examine the dynamic transition of these clusters. Are those in the largest, most homogeneous cluster slowly dividing into the other clusters, or are farmers becoming more homogeneous over time? It would be interesting to explore algorithms that could predict individual farmers into a particular management strategy profile (cluster). Given the demographics in our clusters are similar across many of the clusters, future research should look at other demographic and psychographic factors that might improve the classification of individual farmers. This additional research would help input and service providers tailor offerings to meet the needs of farmers in different strategy profiles.

\section{References}

Alexander, C., C. Wilson, and D. Foley. “Agricultural Input Market Segments: Who is Buying What?” Journal of Agribusiness 23(2005):113-132.

Alexander, C., M. Boehlje, S. Downey, A. Gray, M. Gunderson, and M. Roucan-Kane. "Serving Producers in Volatile Times: Report from the 2008 Large Commercial Producer Survey.” Working Paper 09-09, Purdue University, 2009.

Borchers, B., M. Roucan-Kane, C. Alexander, M.D. Boehlje, W.S. Downey, and A.W. Gray. "How Large Commercial Producers Choose Input Suppliers: Expendable Products from Seed to Animal Health." International Food and Agribusiness Management Review 15(2012):1-20

Brentari, E., L. Dancelli, and M. Manisera. "Clustering Ranking Data in Market Segmentation: A Case Study on the Italian McDonald's Customers' Preferences.” Journal of Applied Statistics 43(2016):1959-1976.

Gloy, B.A. and J.T. Akridge. "Computer and Internet Adoption on Large Us Farms." The International Food and Agribusiness Management Review 3(2000):323-338.

Gloy, B.A., and J.T. Akridge "Segmenting the Commercial Producer Marketplace for Agricultural Inputs." The International Food and Agribusiness Management Review 2(1999):145-163.

Gloy, B.A., J.T. Akridge, and L.D. Whipker "Sources of Information for Commercial Farms: Usefulness of Media and Personal Sources." The International Food and Agribusiness Management Review 3(2000):245-260.

Holland, J.K., N. Widmar, D.A. Widmar, D.L. Ortega, and M. Gunderson. "Understanding Producer Strategies: Identifying Key Success Factors of Commercial Farms in 2013." Paper presented at the Annual Meeting of the Southern Agricultural Economics Association, Texas, 2014.

Hooper, M.A. “Segmentation of the Market for Agricultural Inputs: A Nested Approach.” M. S. thesis, Purdue University, West Lafayette, Indiana, 1994.

Kastens, T.L., K.C. Dhuyvetter, and H. Nivens "Management Factors: What Is Important, Prices, Yields, Costs, or Technology Adoption?” Oklahoma Cooperative Extension Service, 2002.

Kaufman, L. and P. J. Rousseeuw. Finding Groups in Data: An Introduction to Cluster Analysis. Hoboken: John Wiley \& Sons, 2009.

Lai, J., N. Widmar, M. Gunderson, D. A. Widmar, and D. L. Ortega. "Prioritization of Farm Success Factors by Commercial Farm Managers." International Food and Agribusiness Management Review 21(2018):817-832.

McBride, W.D. and J.D. Johnson. "Defining and Characterizing Approaches to Farm Management." Journal of Agricultural and Applied Economics 38(2006):155-167.

Nivens, H.D., T.L. Kastens, and K.C. Dhuyvetter. "Payoffs to Farm Management: How Important Is Crop Marketing?" Journal of Agricultural and Applied Economics 34(2002):193-204.

Ringelberg, J., M. Gunderson, D. Widmar "Strategies and Time Allocation of Large, Commercial Agricultural Producers." Journal of the ASFMRA 2016(2016):202-221. 
Tarsitano, A. "Comparing the effectiveness of rank correlation statistics." Working papers, Universita della Calabria, Dipartimento di Economia e Statistica, 2009.

Treacy, M. and F. Wiersma. "Customer Intimacy and Other Value Disciplines." Harvard Business Review 71(1993): 84-93.

Vilsack, T. and J. Reilly. “Census of Agriculture: Farm Topology.” Washington, DC: United States Department of Agriculture, 2012.

Walter, G. "A “Curious Blend”: The Successful Farmer in American Farm Magazines 1984-1991." Agriculture and Human Values 12(1995):55-68.

Walter, G. “The Ideology of Success in Major American Farm Magazines, 1934-1991.” Journalism \& Mass Communication Quarterly 73(1996):594-608.

Walter, G. "Images of Success: How Illinois Farmers Define the Successful Farmer." Rural Sociology 62(1997):48-68.

\section{Appendix A. Survey instrument}

1. Are you primarily a livestock or a crop producer?

- Livestock

- Crop

2. For livestock producers:

How large is your farming operation?

How large do you expect it to be in 5 years (complete appropriate boxes below)?

\begin{tabular}{l|ll|l|l}
\hline \multicolumn{2}{l|}{ Livestock } & This year & In 5 years \\
\hline Dairy & Cows milked per year & & \\
\hline Dairy & Owned heifers fed per year & $(\#)$ & & \\
\hline Dairy & Custom heifers fed per year & & \\
\hline Beef & Finished cattle marketed per year $\quad(\#)$ & & \\
\hline Beef & Feeder/stock cattle marketed per year $\quad(\#)$ & & \\
\hline Beef & Custom cattle fed per year & $(\#)$ & \\
\hline Hog & Finished hogs marketed per year $\quad(\#)$ & & \\
\hline Hog & Swine feeder pigs marketed per year $\quad(\#)$ & & \\
\hline
\end{tabular}

3. For crop producers:

How large is your farming operation?

How large do you expect it to be in 5 years (complete appropriate boxes below)?

\begin{tabular}{l|l|l}
\hline Crops & This year (acres planted) & In 5 years (acres planted) \\
\hline Corn & & \\
\hline Soybeans & & \\
\hline Wheat, barley, other small grain & & \\
\hline Cotton & & \\
\hline Potatoes & & \\
\hline Tomatoes & & \\
\hline Other fruits and vegetables & & \\
\hline
\end{tabular}


4. When managing your farm business, which of the following activities is the most important to your SUCCESS as a farmer? Please rank your responses from 1 to 5 , where 1 is "the most important" and 5 is "the least important."

- Managing people

- Managing production

- Managing/controlling costs

- Managing output prices

- Managing land, equipment, and facilities

5. What is the highest level of education you have completed?

- Less than high school

- High-school graduate

- 2-year degree

- 4-year degree

- Master's degree

- Doctorate

6. What is your gender?

- Male

- Female

7. What year were you born?

8. Who is primarily responsible for doing the following tasks (check appropriate box)?

$\begin{array}{ccccc} & \text { Myself } & \text { Farm employee } & \text { Don't do it } & \text { Contractor } \\ \text { Marketing } & \square & \square & \square & \square\end{array}$

9. In which states is your farm business located (use state abbreviations)?

Cite this article: Etumnu C and Gray AW (2020). A Clustering Approach to Understanding Farmers' Success Strategies. Journal of Agricultural and Applied Economics 52, 335-351. https://doi.org/10.1017/aae.2020.4 